\title{
SUBSISTENCE DEMYSTIFIED
}

\author{
Arnold Cusmariu
}

In The Problems of Philosophy, Russell held that universals do not exist, they subsist. In the same work, he held also that universals are nonetheless "something."I This is very puzzling. For if universals are "something," then they exist. But then they cannot very well exist and also not exist. Or was Russell suggesting that there is a second meaning of the term "exist," that expressed by the term "subsist?" But this too is problematic, for it is hard to make clear what this second meaning might be. 2

That universals should be thought to enjoy a special mode of being is a traditional idea which likely has its source in Plato's famous thesis that Forms have greater reality than individual things. 3 Like Russell's formulation, it too conflicts with an obvious and quite correct intuition: existence, insofar as we understand it at all, is an all-or-nothing affair. Something either exists or else it does not, simpliciter. There is no. room here for the idea that something exists to a greater, or lesser, degree than something else. of course, we can have properties which are exemplified by some things to a greater degree than they are exemplified by other things, as when a ripe tomato is said to exemplify redness to a greater degree than a less ripe one. But typically this just means that one thing can exemplify a darker shade of red than another. Existence, however, is not like shades or red. It does not come in shades at all.

Plato's thesis is hard to accept as it stands. Nonetheless, there are some intuitions behind it which are as hard to reject as the intuition that existence does not admit of degrees. Universals, philosophers have rightly felt, must be radically different sorts of entities from individual things because they are abstract, eternal, exist necessarily and, above all, are what can be "in the many," to use Aristotle's telling phrase. None of these characterizations apply, or could apply, to individual things. The difference has seemed, upon reflection, to be so great as to warrant the further attribution of one kind of being to universals and another kind of being to individual things. 
The distinction between existence and subsistence and Plato's degrees of reality thesis, then, share a common intuitive motivation. In fact, the former can be regarded as but a modern replacement of the latter. Russell, as a good Platonist, duly echoes the Platonic influence.

Unfortunately, the replacement is no better of than the original. The distinction between existence and subsistence, insofar as it implies that there must be two meanings of "exist," is not any clearer than talk about degrees of reality.

I will argue in this paper, however, that there is a way to do justice to Russell's (and Plato's) intuition that there is something special about the mode of being of universals which does not imply duovocalis $\mathrm{m}^{4}$ with respect to the concept of existence, the concept usually represented by quantifiers. I will show both that we can have two kinds of existents without two concepts of existence and that good logical sense can be made of this Platonist intuition.

The passage in which Russell seems to be leaning towards duovocalism is this:

We shall find it convenient only to speak of things existing when they are in time, that is to say, when we can point to some time at which they exist (not excluding the possibility of their existing at all times). Thus thoughts and feelings, minds and physical objects exist. But universals do not exist in this sense; we shall say that they subsist or have being, where 'being' is opposed to 'existence' as being timeless. The world of universals, therefore, may also be described as the world of being (Russell, pp. 99-100).

Russell is making here two different points at once which I shall try to distinguish.

First, Russell claims that we must distinguish between the concept of existence which applies to ". . . thoughts and feelings, minds and physical objects," and the concept of existence which applies to universals. Second, he justifies the need for drawing this distinction by pointing to the temporality of the objects falling under the first concept as opposed to the nontemporality of the objects falling under the second, according to hitn a significant enough difference between these objects to warrant a difference in mode of existence. 
Temporality is the means by which Russell intends to distinguish the mode of being of universals from that of individual things. We may draw this distinction while preserving univocalisin with respect to existence as follows:

D1. $\underline{a}$ exists $=D F(E y)(y=\underline{a})$
$D 2 . \quad \underline{a}$ subsists $=D f(E y)(y=\underline{a} \varepsilon(z)(T z+z \neq y))$
$D 3 . \quad \underline{a}$ texists $=D f(E y)(T y \& y=\underline{a})$

(where "T" abbreviates "is a temporal object.") 5

Thus instead of saying that universals do not exist but subsist Russell can now say, quite consistently with the intuitions expressed in the above passage, that universals do not texist but subsist--and that individual things texist not subsist. Thus the appearance of contradiction is dispelled.

On this view of Russell's distinction between existence and subsistence universals and individual things can be thought to belong to different ontological orders without existing in different senses. The accounts of subsistence and texistence set forth in D2 and D3 do not, as promised, imply duovocalism with respect to this basic sense of "exist," the sense set forth in Dl. On the contrary, these definitions presuppose a uniform meaning of identity and of the existential quantifier.

A general principle concerning existents which is in keeping with Russell's early Realism emerges out of these considerations. It is that there are two and only two kinds of existents: texistents and subsistents. Thus it is a necessary truth that

$(P R)(x)(x$ exists $+(x$ subsists $v x$ texists $))$.

We have in PR a precise statement of the view sometimes associated with Platonic Realism that reality is fundamentally dulaistic; that, as Plato himself puts it, ". . there is no further thing distinct from the one and the Others; when we have named the One and the others, we have named all things."6

It is worth noting that the distinction between the universals existence, subsistence and texistence drawn in the above definitions also has a syntactical aspect. For it shows up in the logical form of the open sentences expressing them. The first is exprosserl by the open sentence " $(E y)(y=x)$," the second by the open sentence " $(: y)(y=x \in(z)(T z+z \neq x))$," and the third by the open sentence " $(E y)(T y \& y=x)$." Thus jt might be said existence is a simple or pure property, 7 while subsis- 
tence and texistence being built up logically out of it and other ingredients are complex.

To sum up, I have argued that we can understand the Platonistic intuition that universals and individual things have different modes of being without implying that there is more than one fundamental concept of existence. I realize, of course, that it is still an open question whether anything subsists. 8 My definitions do not settle this issue. Nor do these definitions attempt to distinguish between the various kinds of universals which may be said to subsist in the sense specified, between predicables such as qualities and relations, and non-predicables such as propositions, numbers and sets. These are different problems. Hine has been only how to demystify subsistence. 9

University of Rhode Island 
NOTES

"It [the relation "north of"] is neither in space nor in time, neither mental nor material; yet it is something," p. 98 .

2Thus Gustav Bergmann: ". . . I understand [none] but the most strictly univocal use of 'exist," Realism (University of Wisconsin Press, 1967), p. 3. Another prominent strict univocalist is, of course, Quine. See also $A$. C. Ewing, The Fundamental Questions of Philosophy (Collier Books, 1962), p. 235, and A. D. Woozley, Theory of Knowledge (Hutchinson $\&$ Co., 1949), p. 75, for further qualms about the intelligibility of a second meaning of "exist."

${ }^{3}$ Commentators have not overlooked this puzzling thesis. See 6. Vlastos, "Degrees of Reality in Plato," in R. Bambrough (ed.), New Essays on Plato and Aristotle

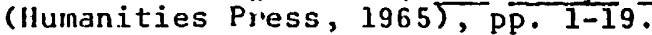

"The terin is Morton White's. See Toward Reunion in Philosophy (llarvard University Press, 1956), p. 61.

5 The quantifiers in these definitions function objectionally not substitutionally, as is evident from D1. This does not beg the question against Russell since he does not deny objectuality to universals.

${ }^{6}$ Parmenides $159 B-C$, Cornford translation. Plato uses the expression "the One" when speaking about Forms, and the expression "the 0thers" when speaking about individual exemplifying things.

7 plato himself, it should be noted, held that existence was a property. See Parmenides 142B, Theaetetus $186 \mathrm{~A}$ and Sophist $259 \bar{A}$.

${ }^{8}$ I have tried to close this question in my dissertation, $\Lambda$ Platonist Theory of Properties, Brown University, $1.9 \overline{7} 7$.

9. Mhanks to the editors, to P. L. Quinn and to Josiah Strandberg for helpful comments. 